\title{
Contextual Variables and Time-Motion Analysis in Soccer
}

Authors

Affiliations

\section{J. Castellano ${ }^{1}$, A. Blanco-Villaseñor ${ }^{2}$, D. Álvarez}

${ }^{1}$ Basque Country University, Physical Activity and Sport, Vitoria-Gasteiz, Spain

${ }^{2}$ Barcelona University, Methodology of the Behavioural Sciences, Barcelona, Spain
Key words

soccer

- work-rate

- performance analysis

- multivariate model

- situational variables accepted after revision

January 20, 2011

\section{Bibliography}

Dol http://dx.doi.org/

10.1055/s-0031-1271771

Published online: 2011

Int J Sports Med

(c) Georg Thieme

Verlag KG Stuttgart - New York

ISSN 0172-4622

\section{Correspondence}

\section{Julen Castellano, PhD}

Basque Country University

Physical Activity and Sport

C/ Lasarte 71

01007 Vitoria-Gasteiz

Spain

Tel.: + 34/945/0135 25

Fax: + 34/945/013501

julen.castellano@ehu.es

\section{Abstract}

$\nabla$

Using a multi-camera computerised tracking system the present study aimed to provide a detailed analysis of the work-rate profile of a team of elite soccer players during official matches of the Spanish Premier League. Observation-based performance measures were obtained from 434 individual samples. 6 physical parameters involving the distance covered by players were analysed: standing intensity $\left(0-11 \mathrm{~km} \cdot \mathrm{h}^{-1}\right)$, lowintensity running $\left(11.1-14 \mathrm{~km} \cdot \mathrm{h}^{-1}\right)$, moderateintensity running $\left(14.1-17 \mathrm{~km} \cdot \mathrm{h}^{-1}\right)$, high-intensity running $\left(17.1-21 \mathrm{~km} \cdot \mathrm{h}^{-1}\right)$, very high-intensity run$\operatorname{ning}\left(21.1-24 \mathrm{~km} \cdot \mathrm{h}^{-1}\right)$ and sprinting $\left(>24 \mathrm{~km} \cdot \mathrm{h}^{-1}\right)$. These intensity thresholds were considered with

\section{Introduction}

$\nabla$

Analysis of movement patterns during matchplay has been used to evaluate physical demands in soccer for more than 30 years [33]. However, the work-rate profile can be altered as a result of many factors, including the method used by different systems of time motion analysis [29]. In this regard, a recent review suggests that both different techniques used to analyse work rate and 'situational' variables (such as match location or status and the quality of the opposition, among others) have an important influence on measures of soccer performance $[6,17,39]$. As such, the effective assessment of players or teams requires knowledge of the contextual factors $[20,21,28,39]$ that can potentially affect performance [31].

One of these variables is the halves of the game. Previous studies $[2,27,34]$ have reported that a longer distance is covered during the first half of the match compared to the second half, although the results are not entirely consistent $[4,11,41]$. These inconsistent findings are probably to do with the interaction of other variables such as respect to 4 contextual variables: match status, match location, opponent level and match half, which were analysed in relation to the effective playing time. A descriptive analysis and a multivariate mixed model were employed for the analysis of change processes in soccer. The distance total covered $(\mathrm{m})$ by players at different work intensities during the effective playing time was greater when playing at home (3931 vs. 3887 away), when the reference team was losing (3975 vs. 3837 drawing and 3921 winning) and when the level of the opposing team was higher (4032 vs. 3938 medium and 3736 bottom). By contrast, their physical performance decreased during the $2^{\text {nd }}$ half of matches ( 3822 vs. 3985 $1^{\text {st }}$ half). research designs, instruments or analytic techniques [6,29].

Match status is another factor that has attracted increasing attention in the scientific literature on soccer performance [39]. This factor is defined as "winning", "drawing" or "losing" in relation to the number of goals scored and conceded by the sampled team at the time of data entry $[17,21]$. Some studies have considered this situational variable (score) when analysing the physical activity of players $[6,24]$.

There has also been considerable research into home advantage [25], the results suggesting that teams gain a higher percentage of overall points when playing at home $[23,26,37,38]$. However, few studies have considered how playing at home influences the work-rate profiles in combination with other variables, although it seems that home teams cover a greater distance than do away teams during low-intensity activity $[20,41]$.

Finally, the opponent level has been investigated with regards to differences in physical ability between players of the best and worst teams in the same league [40], or as a function of their opponent level [27]. It is likely that differences in 
players' physical activities are due to the tactics and style of play adopted, although this variable must be studied independently. In the context of the above, the present research takes a novel approach in 2 respects. Firstly, it uses multivariate analysis to study the interaction between distances covered at different work intensities and contextual variables. Secondly, it makes use of the effective playing time, i.e., the time when the ball is in play, in order to study the workload of professional soccer players. On the one hand, it is likely that the variability of results reported for the physical workload $[20,22,27]$ of players in different matches is due to variability in the total playing time. However, previous methods have not addressed the effective playing time, even though this tends to be longer during the first half; this is in contrast to the total playing time, which is usually greater in the second half [9]. The distinction between effective and total playing time would therefore seem to be relevant in terms of elucidating the differential effects on players' physical profile.

In summary, the aim of the study was to determine physical performance profiles in soccer by observing a professional team in competitive matches, analysed from the perspective of effective playing time $\left(\mathrm{E}_{\mathrm{t}}\right)$. Specifically, the study sought to identify the interactive effects of match location (home vs. away), score (win, draw and lose), opponent level (top, medium and bottom) and match half (first vs. second) on work-rates.

\section{Material and Methods}

$\nabla$

\section{Participants}

A multi-camera computerised tracking system (AMISCO Pro ${ }^{\circledR}$, version 1.0.2., Nice, France) was used to gather data from Spanish Premier League players completing an entire match half (434) during the 2005-06 season. Data were collected for the duration of each match half, including injury time. The reliability and validity of this semi-automatic tracking system has been evaluated in other studies $[11,12,41]$. The club in question gave permission for this information to be used. However, to ensure team and player confidentiality, all data were desensitised before analysis and were processed in accordance with the Declaration of Helsinki [15]. Institutional approval for the study was given by the ethics committee of the University of the Basque Country.

\section{Total and effective playing time}

Total playing time $\left(\mathrm{T}_{\mathrm{t}}\right)$ was defined as the duration of the match as a whole, including stoppage time. Effective playing time $\left(\mathrm{E}_{\mathrm{t}}\right)$ refers to the duration of play after subtracting the time taken up by stoppages, substitutions, goals and injuries, etc., in other words, subtracting the amount of time in which the ball is out of play.

\section{Movement categories and intensity thresholds}

In line with other studies $[2,10,12,27,41]$ matches were analysed by distinguishing a set of activity categories. Specifically, the following 6 match performance parameters were analysed with respect to the distance covered: standing intensity (standing, walking, jogging) (SD, $\left.0-11 \mathrm{~km} \cdot \mathrm{h}^{-1}\right)$; low-intensity running (LD, $11.1-14 \mathrm{~km} \cdot \mathrm{h}^{-1}$ ); moderate-intensity running (MD, 14.1$\left.17 \mathrm{~km} \cdot \mathrm{h}^{-1}\right)$; high-intensity running ( $\left.\mathrm{HD}, 17.1-21 \mathrm{~km} \cdot \mathrm{h}^{-1}\right)$; very high-intensity running (VHD, 21.1-24 $\mathrm{km} \cdot \mathrm{h}^{-1}$ ); and sprinting $\left(\mathrm{SpD},>24 \mathrm{~km} \cdot \mathrm{h}^{-1}\right)$.

\section{Contextual variables}

4 independent variables were included in the research. With respect to the contextual variable match location, and in line with previous studies [2], we distinguished between matches played at home and away. As regards the match halves these were also divided into 2 levels: first and second half. With respect to the opponent level we examined differences in physical performance when the reference team played against successful teams (ranked in the top 6 league positions), moderately successful teams (ranked $7^{\text {th }}$ to $13^{\text {th }}$ in the league) and the least successful teams (ranked in the bottom 7 of the league). These categories are similar to those reported previously [28,39]. With respect to the partial and final result or match status [21], this was divided into 3 levels, i.e., whether a team wins, loses or draws in each half.

\section{Statistical analyses}

Data are presented as the mean \pm standard deviation $( \pm S D)$, along with the $95 \%$ confidence interval $(95 \% \mathrm{CI})$. Initial statistical analyses were performed using SPSS for Windows version 17.0 (SPSS Inc., Chicago, IL, USA). Differences in match time (total and effective) with respect to the 4 independent variables were determined using the Student's t-test (halves and match location) and a one-way analysis of variance (opponent level and score). When a significant F-value was found, Bonferroni's posthoc tests were applied. The level of statistical significance was set at $p<0.05$.

A multivariate mixed model using SAS for Windows 9.1 [35] was also applied to analyse the change processes in soccer. A linear mixed model is a parametric linear model for clustered, longitudinal or repeated-measures data that quantifies the relationships between a continuous dependent variable and various predictor variables. Longitudinal data differs from traditional multivariate data, in which a number of measurements are collected for each subject before analysing the multiple measurements as a single multivariate outcome. Here, Mauchly's test of sphericity was used to determine, firstly, that the data could be treated as multivariate (transformed variables, $X^{2}=21675.6$; Pr $>$ ChiSq < 0.0001 ) and, secondly, that they fulfilled the criterion of orthogonality $\left(X^{2}=8340.2\right.$; $\left.\mathrm{Pr}>\mathrm{ChiSq}<0.0001\right)$. Both tests were significant, thus confirming the suitability of a multivariate procedure.

\section{Results}

$\nabla$

\section{Total and effective playing time}

The average total duration $\left(T_{t}\right)$ of each half was $46 \mathrm{~min} 32 \mathrm{~s}$ $( \pm 44 \mathrm{~s})$ for first halves and $48 \mathrm{~min} 35 \mathrm{~s}( \pm 1 \mathrm{~min} 4 \mathrm{~s})$ for second halves, while the mean effective playing time $\left(\mathrm{E}_{\mathrm{t}}\right)$ in each half was $26 \min 19 \mathrm{~s}( \pm 2 \mathrm{~min} 39 \mathrm{~s})$ and $26 \mathrm{~min} 4 \mathrm{~s}( \pm 2 \mathrm{~min} 25 \mathrm{~s})$, respectively ( $\bullet$ Table 1 ). The time during which the ball was in play did not reach $55 \%\left(E_{t} / T_{t} \%\right)$ of the total match duration, independently of the contextual variables. There were significant differences in the $\mathrm{T}_{\mathrm{t}}$ with respect to the variables halves, match location and score, as well as in the $\mathrm{E}_{\mathrm{t}}$ with respect to the variable opponent level.

\section{Distance covered}

When considering the whole match, the total distance covered by players in each half ranged between $3871 \mathrm{~m}$ and $3958 \mathrm{~m}$ during the effective playing time, which corresponds to $69 \%$ of the 
Table 3 Mean distances covered in metres $(\mathrm{m})$, standard deviations $( \pm S D)$ and confidence intervals $(95 \% \mathrm{Cl})$ with respect to the different movement categories and to the effective playing time $\left(E_{t}\right)$ achieved by elite soccer players for each match half in relation to the 4 contextual variables.

\begin{tabular}{|c|c|c|c|c|c|c|c|c|}
\hline & & & & & Inten & gory & & \\
\hline & & & SpD & VHD & HD & MD & LD & SD \\
\hline & $1^{\text {st }}$ half & mean $(m)$ & 116.3 & 140.3 & 417.9 & 524.5 & 745.8 & 2039.7 \\
\hline & & $\pm S D$ & 75.2 & 60.7 & 131.8 & 162.1 & 162.4 & 264.3 \\
\hline & & $95 \% \mathrm{Cl}$ & 106.9 & 132.7 & 401.4 & 504.2 & 725.5 & 2006.6 \\
\hline halves & & & 125.7 & 147.9 & 434.4 & 544.7 & 766.1 & 2072.8 \\
\hline & $2^{\text {nd }}$ half & mean $(m)$ & 107.0 & 131.9 & 390.5 & 484.2 & 692.2 & 2016.4 \\
\hline & & $\pm \mathrm{SD}$ & 70.4 & 56.8 & 139.1 & 145.0 & 150.3 & 228.4 \\
\hline & & $95 \% \mathrm{Cl}$ & 96.8 & 123.7 & 370.4 & 463.2 & 670.5 & 1983.3 \\
\hline & & & 117.2 & 140.2 & 410.6 & 505.2 & 714.0 & 2049.4 \\
\hline & top (1) & mean $(\mathrm{m})$ & 114.8 & 143.5 & 416.6 & 525.0 & 746.5 & 2086.0 \\
\hline & & $\pm S D$ & 71.8 & 59.3 & 143.4 & 169.5 & 168.1 & 255.5 \\
\hline & & $95 \% \mathrm{Cl}$ & 103.4 & 134.0 & 393.8 & 498.0 & 719.7 & 2045.3 \\
\hline & & & 126.3 & 152.9 & 439.4 & 551.9 & 773.3 & 2126.7 \\
\hline & medium (2) & mean $(\mathrm{m})$ & 117.2 & 136.7 & 411.2 & 508.1 & 722.7 & 2042.0 \\
\hline opponent level & & $\pm S D$ & 75.3 & 57.4 & 135.2 & 151.9 & 165.9 & 290.5 \\
\hline & & $95 \% \mathrm{Cl}$ & 105.4 & 127.8 & 390.0 & 484.3 & 696.8 & 1996.5 \\
\hline & & & 129.0 & 145.7 & 432.3 & 531.9 & 748.7 & 2087.5 \\
\hline & bottom (3) & mean $(\mathrm{m})$ & 102.7 & 128.1 & 386.4 & 483.4 & 692.9 & 1942.0 \\
\hline & & $\pm S D$ & 71.9 & 60.8 & 124.0 & 141.2 & 133.3 & 135.4 \\
\hline & & $95 \% \mathrm{Cl}$ & 89.8 & 117.1 & 364.1 & 458.0 & 668.9 & 1917.6 \\
\hline & & & 115.7 & 139.0 & 408.7 & 508.8 & 716.9 & 1966.4 \\
\hline & home & mean $(\mathrm{m})$ & 118.9 & 136.3 & 403.0 & 508.6 & 728.4 & 2035.6 \\
\hline & & $\pm S \mathrm{SD}$ & 75.1 & 59.0 & 139.8 & 157.4 & 162.1 & 258.6 \\
\hline & & $95 \% \mathrm{Cl}$ & 110.0 & 129.4 & 386.5 & 489.9 & 709.2 & 2005.0 \\
\hline & & & 127.8 & 143.3 & 419.5 & 527.2 & 747.6 & 2066.2 \\
\hline match Iocatıon & away & mean $(\mathrm{m})$ & 100.7 & 137.3 & 411.8 & 504.8 & 713.1 & 2019.4 \\
\hline & & $\pm S D$ & 68.4 & 59.6 & 127.7 & 154.4 & 154.4 & 233.1 \\
\hline & & $95 \% \mathrm{Cl}$ & 89.9 & 127.9 & 391.7 & 480.5 & 688.7 & 1982.6 \\
\hline & & & 111.5 & 146.7 & 431.9 & 529.1 & 737.4 & 2056.1 \\
\hline & lose (1) & mean $(\mathrm{m})$ & 117.1 & 146.3 & 430.0 & 525.5 & 729.4 & 2026.5 \\
\hline & & $\pm S D$ & 67.7 & 53.7 & 133.6 & 153.7 & 158.9 & 251.4 \\
\hline & & $95 \% \mathrm{Cl}$ & 106.9 & 138.2 & 409.8 & 502.3 & 705.4 & 1988.5 \\
\hline & & & 127.3 & 154.4 & 450.2 & 548.7 & 753.4 & 2064.4 \\
\hline & draw (2) & mean $(m)$ & 111.3 & 131.2 & 372.4 & 475.2 & 700.3 & 2046.9 \\
\hline & & $\pm \mathrm{SD}$ & 73.3 & 58.6 & 132.4 & 152.5 & 166.4 & 290.2 \\
\hline match status & & $95 \% \mathrm{Cl}$ & 99.1 & 121.4 & 350.3 & 449.8 & 672.6 & 1998.6 \\
\hline & & & 123.5 & 140.9 & 394.4 & 500.6 & 728.0 & 2095.2 \\
\hline & win (3) & mean $(m)$ & 106.9 & 129.7 & 411.9 & 518.5 & 739.7 & 2014.3 \\
\hline & & $\pm \mathrm{SD}$ & 80.4 & 65.6 & 134.8 & 159.2 & 149.8 & 189.7 \\
\hline & & $95 \% \mathrm{Cl}$ & 92.5 & 117.9 & 387.7 & 490.0 & 712.9 & 1980.3 \\
\hline & & & 121.3 & 141.5 & 436.0 & 547.0 & 766.6 & 2048.3 \\
\hline
\end{tabular}

and with respect to 4 situational variables (halves, score, opponent level and match location) that were analysed simultaneously.

Our results are consistent with recent investigations using sophisticated measurement technologies $[10,20]$ and which demonstrate that the mean distance covered by male elite outfield players for each half is $\sim 5600 \mathrm{~m}$ in $\mathrm{T}_{\mathrm{t}}$, but only $\sim 3900 \mathrm{~m}$ in $\mathrm{E}_{\mathrm{t}}$ (० Table 2 ), equivalent to $69 \%$. In the $T_{t}$, our data show a workrate profile similar to that reported in other studies of Spanish Premier League players $[10,12,20,41]$. Mean values for physical demands are also close to the mean values obtained in studies of players in the Italian Serie A [10,22], the English Premier League $[4,10]$, the German Championship [10] and the Swedish professional league [1]. However, they contrast with those reported by Rienzi et al. [34], who found that international South American players covered less total distance during a game.

The present paper is the first to report external workload distances for intense movement when taking into account the effective playing time $\left(\mathrm{E}_{\mathrm{t}}\right)$. The $\mathrm{E}_{\mathrm{t}}$ accounts for a little over $50 \%$ of the total match time $\left(\mathrm{T}_{t}\right)$, it being the only time during which teams have the opportunity to alter the score. In support of this notion a time-motion analysis based on $\mathrm{E}_{\mathrm{t}}(\sim 70 \%$ of workload corresponds to this period) can provide more precise information about a player's physical activity, which may have direct repercussions on the match outcome. In this regard we found significant differences with respect to the duration of the $T_{t}$ but not for the $E_{t}$. This suggests that it would be useful to evaluate players' activity on the basis of the $E_{t}$, since this measure remains more stable across matches ( $\bullet$ Table 1 ); this would eliminate the possible variability between matches that is associated with the $T_{t}$, such as in matches where the home team is losing and the referees prolong the $\mathrm{T}_{\mathrm{t}}[36]$.

The second noteworthy aspect of the present study is that we applied a multivariate analysis including contextual variables, those hypothesised to affect the physical performance of players. The players' work-rates showed some significant differences in relation to the situational variables ( $\odot$ Table 4 , within-subjects effects). In soccer, the evidence for a difference in the total dis- 
Table 4 General linear model (GLM) procedure and repeated-measures analysis of variance for the contextual variables.

\begin{tabular}{|c|c|c|c|c|c|c|}
\hline \multicolumn{7}{|c|}{ Hypothesis tests for between-subjects effects } \\
\hline Facet & DF & Type III SS & Mean square & F-Value & $\mathrm{Pr}>\mathrm{F}$ & \\
\hline match location & 1 & 107444.8 & 107444.80 & 3.4 & 0.0661 & \\
\hline opponent level & 2 & 4875664.7 & 2437832.37 & 76.7 & $<0.0001$ & \\
\hline half & 1 & 2809417.0 & 2809417.02 & 88.4 & $<0.0001$ & \\
\hline match status & 2 & 1270662.9 & 635331.49 & 19.9 & $<0.0001$ & \\
\hline error & 2597 & 82567969.6 & 31793.60 & & & \\
\hline \multicolumn{7}{|c|}{ Hypothesis tests for within-subjects effects } \\
\hline Facet & DF & Type III SS & Mean square & F-Value & $\mathrm{Pr}>\mathrm{F}$ & \\
\hline workload (WL) & 5 & 5805498772 & 1161099754 & 58233.8 & $<0.0001$ & \\
\hline $\mathrm{WL}^{*}$ match location & 5 & 243321 & 48664 & 2.4 & 0.0322 & \\
\hline WL*opponent level & 10 & 6134952 & 613495 & 30.8 & $<0.0001$ & \\
\hline $\mathrm{WL}^{*}$ half & 5 & 1070249 & 214050 & 10.7 & $<0.0001$ & \\
\hline WL* match status & 10 & 3916993 & 391699 & 19.7 & $<0.0001$ & \\
\hline error (workload) & 12985 & 258902615 & 19939 & & & \\
\hline Facet & SpD & VHD & HD & MD & LD & SD \\
\hline match location $\dagger$ & $1>2$ & $2>1$ & $2>1$ & $1>2$ & $1>2$ & $1>2$ \\
\hline opponent level & $2>1>3$ & $1>2>3$ & $1>2>3$ & $1>2>3$ & $1>2>3$ & $1>2>3$ \\
\hline half & $1>2$ & $1>2$ & $1>2$ & $1>2$ & $1>2$ & $1>2$ \\
\hline match status & $1>2>3$ & $1>2>3$ & $1>3>2$ & $1>3>2$ & $3>1>2$ & $2>1>3$ \\
\hline
\end{tabular}

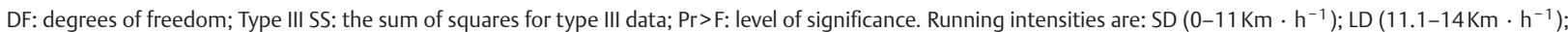
MD (14.1-17 Km $\left.\cdot \mathrm{h}^{-1}\right)$; HD (17.1-21 Km $\left.\cdot \mathrm{h}^{-1}\right)$; VHD (21.1-24 Km $\left.\cdot \mathrm{h}^{-1}\right)$; and SpD (>24 Km $\left.\cdot \mathrm{h}^{-1}\right)$. Match location was Home (1) and Away (2). Opponent level was Top (1), Medium (2) and Bottom (3). Halves were First (1) and Second (2). Match status was Lose (1), Draw (2) and Win (3). †No significant differences ( $p=0.06$ )

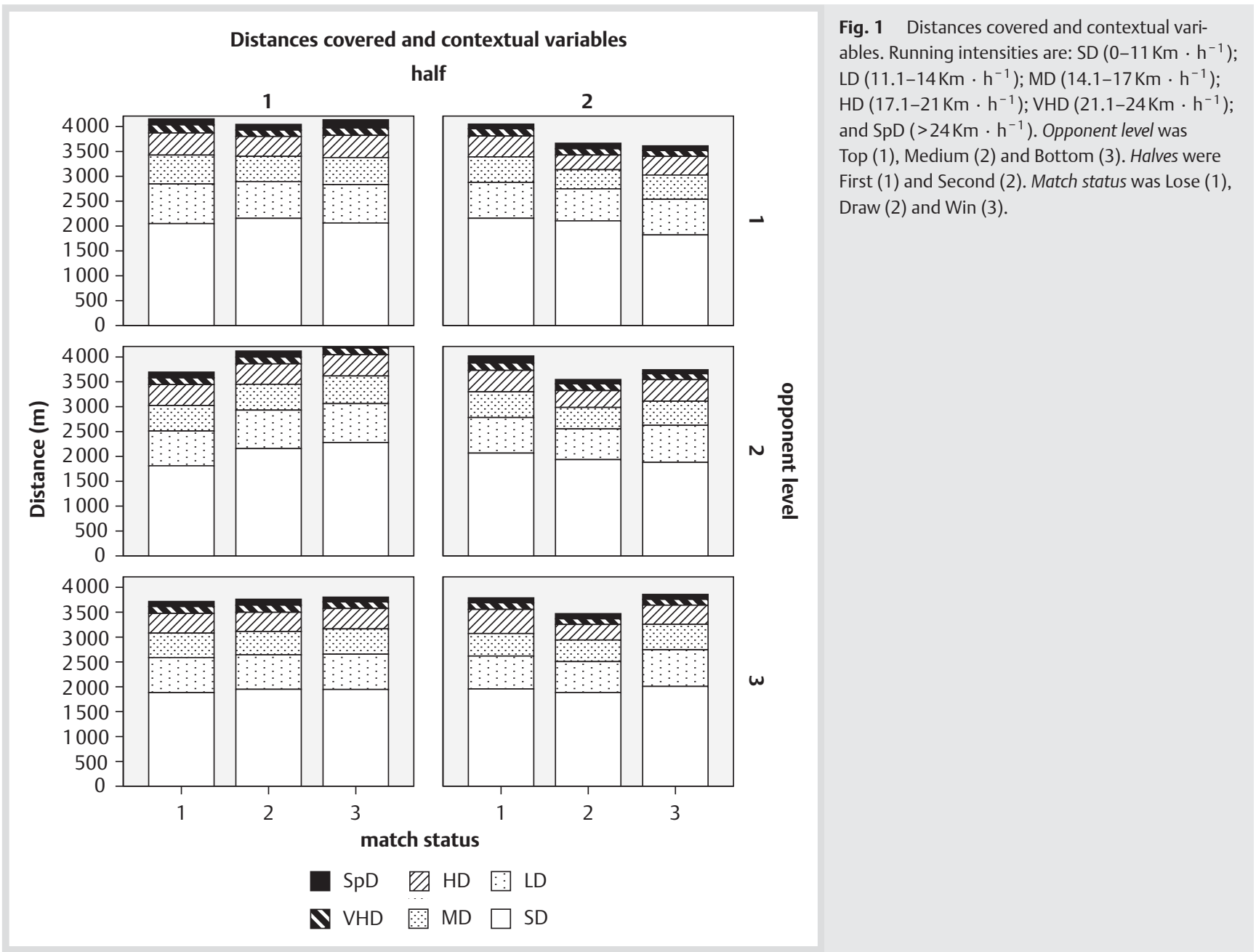


tance covered between halves is inconsistent, and a significant decrement does not necessarily occur in all players [6]. Some studies $[2,5,11,22,34,30]$ have reported that the distance run decreases during the second half, suggesting a form of fatigue [32]. Indeed, recent studies have shown that the amount of both high-intensity running and sprinting declines as a soccer match progresses [14,18]. However, Di Salvo et al. and Zubillaga [11,41] reported just the opposite, while Bradley et al. [4] found no differences for high-intensity running and sprinting. In the present study, significant differences were found between the first- and second-half movement patterns for players' workload in the $\mathrm{E}_{\mathrm{t}}$. These differences in workload occur despite the fact that the duration of the $\mathrm{E}_{\mathrm{t}}$ is similar in the 2 match halves ( $\bullet$ Table 1 ).

With respect to match location (home vs. away), no significant differences were found for distances covered at different intensities. Contrary to the findings of Lago et al. [20] the concept of home advantage does not seem to have repercussions for physical performance $(p=0.06)$. The absence of any differences could be due to the influence of the interaction with the other contextual variables. It should also be noted that for match location, no significant differences were found in the duration of the $E_{t}$ between the games analysed ( $\bullet$ Table 1 ).

With respect to the opponent level, and in line with the findings of other studies $[22,28]$, the poorer the quality of the opponent, the shorter the distance covered by the reference team. However, in contrast to Lago et al. [20], who found that teams playing against better quality teams ran less distance at low intensities (0-11 and $\left.11.1-14 \mathrm{~km} \cdot \mathrm{h}^{-1}\right)$, the present results show that when playing against more successful teams the reference team covered greater distances in all intensity range categories (Top> Medium > Bottom) except for the SpD category (Medium > Top > Bottom), although significant differences were found for the $E_{t}$ (॰ Table 1).

Finally, the physical profile was also influenced by match status. Contrary to Zubillaga [41] but similar to Lago et al. $[19,20]$ it seems that the distances covered (Spd, VHD, HD and MD) by the reference team were greater when the result was adverse ( $ه$ Table 4). This suggests that when losing, players try to reach their maximal physical capacity in order to draw or win the match. Accordingly, players clearly performed less low-intensity activity. Furthermore, this occurred when no significant differences were found for the $E_{t}(\bullet$ Table 1$)$.

A limitation of the present study is that the players' position was not taken into account, in contrast to the approach taken in some previous reports $[3,4,12,13]$. It is likely that the workload of players according to their position is affected differently depending on the contextual variables involved.

It has already been noted that research findings and conclusions often vary across independent studies. Certainly, no one study can measure and control for all extraneous influences, particularly when results may be influenced by different contextual variables [19] that affect players' performance, for example, the type of competition [41], the players' level [22], the playing style of different leagues [34], the match status or the quality of the opponent [20]. The present study only provides a simple overview of the work-rate profiles of elite soccer players by analysing longitudinal data, although it is the first to report a MANOVA analysis. The particular applications of this analysis are useful for identifying contextual dynamics, and it offers empirical clues to the influence of multivariate factors that should not be considered in isolation. If performance is adversely influenced by specific situational variables, possible causes can be examined and match preparation focused on reducing such effects [20]. Identifying physical qualities is a sine qua non among the other attributes needed by athletes to be competitive in the teamsports arena. The present findings suggest that a failure to consider the $E_{t}$ when quantifying the physical workload of players may also affect this. Furthermore, consideration of the effective playing time provides more precise information about competitive physical demands, and this can then be applied to the training context in order to develop drills, etc. that are more closely tailored to actual match requirements [8]. Our results highlight a number of variables that could explain physical workload in soccer players, and combinations of these variables could be used to develop a model for predicting (from a probabilistic viewpoint) the physical activity profile in competition. Indeed, the findings of this study, together with those of other authors $[19,21,39]$, suggest that effective assessment of soccer performance at a behavioural level needs to account for the potential interactions between situational variables.

It is hoped that the present findings will serve to broaden the body of research on physical demands in elite soccer match-play, as well as improving knowledge of specific situational variables and their possible influence as regards tactical preparation for matches. As such, the results could be used to reduce undesirable effects [7] (for example, by preventing a decline in players' performance or avoiding an increased likelihood of injury) or to develop recovery strategies that help players to maintain their performance in soccer.

\section{Acknowledgements}

This study is part of the project entitled Avances tecnológicos y metodológicos en la automatización de estudios observacionales en deporte, funded by Spain's Dirección General de Investigación, Ministerio de Ciencia e Innovación (PSI2008-01179) over the period 2008-2011.

\section{References}

1 Andersson H, Ekblom B, Krustrup P. Elite football on artificial turf versus natural grass: Movement pattern, technical standard and player opinion. J Sports Sci 2008; 26: 113-122

2 Barros RML, Misuta MS, Menezes RP, Figueroa PJ, Moura FA, Cunha SA, Anido R, Leite NJ. Analysis of the distances covered by first division Brazilian soccer players obtained with an automatic tracking method. J Sports Sci Med 2007; 6: 233-242

3 Bloomfield J, Polman R, O'Donoghue P. Physical demands of different positions in FA Premier League soccer. J Sports Sci Med 2007; 6: 63-70

4 Bradley PS, Sheldon W, Wooster B, Olsen P, Boanas P, Krustrup P. Highintensity running in English FA Premier League soccer matches. J Sports Sci 2009; 27: 159-168

5 Burgess DJ, Naughton G, Norton KI. Profile of movement demands of national football players in Australia. J Sci Med Sport 2006; 9: 334-341

6 Carling C, Bloomfield J, Nelsen L, Reilly T. The role of motion analysis in elite soccer: contemporary performance measurement techniques and work rate data. Sports Med 2008; 38: 839-862

7 Carling C, Gall FL, Reilly TP. Effects of physical efforts on injury in elite soccer. Int J Sports Med 2010; 31: 180-185

8 Casamichana D, Castellano J. Time-motion, heart rate, perceptual and motor behaviour demands in small-sides soccer games: Effects of pitch size. J Sports Sci 2010; 28: 1615-1623

9 Castellano J, Perea A, Álvarez D. Transiciones en la posesión del balón en fútbol: de lo posible a lo probable. Apunts 2009; 95: 71-84 [http:// articulos.revista-apunts.com/95/es/095_075-081_es.pdf] 
10 Dellal A. Analysis of the soccer player physical activity and of its consequences in the training: special reference to the high intensities intermittent exercises and the small sided-games. Master's thesis, University of Sports Sciences, Strasbourg, France, 2008

11 Di Salvo V, Baron R, Cardinale M. Time motion analysis of elite footballers in European cup competitions. J Sports Sci Med 2007a; 6: 14-15

12 Di Salvo V, Baron R, Tschan H, Calderon FJ, Bachl N, Pigozzi F. Performance characteristics according to playing position in elite soccer. Sports Med 2007b; 28: 222-227

13 Di Salvo V, Gregson W, Atkinson G, Tordoff P, Drust B. Analysis of high intensity activity in premier league soccer. Int J Sports Med 2009; 30: 205-212

14 Gregson W, Drust B, Atkinson G, Salvo VD. Match-to-Match variability of high-speed activities in Premier League Soccer. Int J Sports Med 2010; 31: 237-242

15 Harriss DJ, Atkinson G. International Journal of Sports Medicine - Ethical Standards in Sport and Exercise Science Research. Int J Sports Med 2009; 30: 701-702

16 Huynh H, Feldt LS. Estimation of the box correction for degrees of freedom from sample data in the randomized block and split plot designs. J Educ Stat 1976; 1: 69-82

17 James $N$, Jones $P$, Mellalieu SD. Possession as a performance indicator in soccer. Int J Perform Anal Sport 2004; 4: 98-102

18 Krustrup P, Mohr M, Steensberg A, Bencke J, Kjaer M, Bangsbo J. Muscle and blood metabolites during a soccer game: Implications for sprint performance. Med Sci Sports Exerc 2008; 38: 1165-1174

19 Lago C. The influence of match location, quality of opposition, and match status on possession strategies in professional association football. J Sports Sci 2009; 27: 1463-1469

20 Lago C, Casais L, Dominguez E, Sampaio J. The effects of situational variables on distance covered at various speeds in elite soccer. Eur J Sports Sci 2010; 10: 103-109

21 Lago C, Martín R. Determinants of possession of the ball in soccer. J Sports Sci 2007; 25: 969-974

22 Mohr M, Krustrup P, Bangsbo J. Match performance of high-standard soccer players with special reference to development of fatigue. J Sports Sci 2003; 21: 519-528

23 Nevill A, Holder R. Home advantage in sport: An overview of studies on the advantage of playing at home. Sport Med 1999; 28: 221-236

24 O'Donoghue PG, Tenga A. The effect of score-line on work rate in elite soccer. J Sports Sci 2001; 19: 25-26

25 Pollard $R$. Home advantage in soccer: A retrospective analysis. J Sports Sci 1986; 4: 237-246
26 Rahnama N, Bambaeichi E, Sadeghiour HR. Home advantage in Asian football. J Sports Sci Med 2007; 6: 209

27 Rampinini E, Coutts AJ, Castagna C, Sassi R, Impellizzeri FM. Variation in top level soccer match performance. Int J Sports Med 2007; 28: 1018-1024

28 Rampinini E, Impellizzeri FM, Castagna C, Coutts AJ, Wisloff U. Technical performance during soccer matches of the Italian Serie A league: Effect of fatigue and competitive level. J Sci Med Sport 2009; 12: 227-233

29 Randers MB, Mujika I, Hewitt A, Santisteban J, Bischoff R, Solano R, Zubillaga A, Peltola E, Krustrup P, Mohr M. Application of four different *football* match analysis systems: A comparative study. J Sports Sci 2010; 28: 171-182

30 Rebelo N, Krustrup P, Soares J, Bangsbo J. Reduction in intermittent exercise performance during a soccer match. J Sports Sci 1998; 16: 482-483

31 Reed D, O'Donoghue P. Development and application of computerbased prediction methods. Int J Perform Anal Sports 2005; 5: 12-28

32 Reilly T. Energetics of high-intensity exercise (soccer) with particular reference to fatigue. J Sports Sci 1997; 15: 257-263

33 Reilly $T$, Thomas $V$. A motion analysis of work-rate in different positional roles in professional football match-play. J Hum Movement Stud 1976; 2: 87-97

34 Rienzi E, Drust B, Reilly T, Carter JEL, Martin A. Investigation of anthropometric and work-rate profiles of elite South American international soccer players. J Sports Med Phys Fit 2000; 40: 162-169

35 SAS Institute Inc. SAS/STAT. Users Guide, Version 8, Chapter 41. Cary, NC: SAS Institute Inc; 1999

36 Scoppa $V$. Are subjective evaluations biased by social factors or connections? An econometric analysis of soccer referee decisions. Empir Econ 2008; 35: 123-140

37 Seckin A, Pollard $R$. Home advantage in Turkish professional soccer. J Sports Sci Med 2007; 6: 203-204

38 Silvério J, Tendais I, Almeida G. Home advantage in Portuguese First League football. J Sports Sci 2004; 22: 517-518

39 Taylor JB, Mellalieu SD, James N, Shearer DA. The influence of match location, quality of opposition, and match status on technical performance in professional association football. J Sports Sci 2008; 26: 885-895

40 Wisløff $U$, Helgerud J, Hoff J. Strength and endurance of elite soccer players. Med Sci Sports Exerc 1998; 30: 462-467

41 Zubillaga A. La actividad del jugador de fútbol en alta competición: análisis de variabilidad. Doctoral thesis, University of Malaga, Spain (in Spanish) 2006 